\title{
Scolia
}

Revue de linguistique

35 | 2021

Superlatifs et définitude

\section{Conditions sur la définitude dans les superlatifs arabes}

Conditions on Definiteness in Arabic Superlatives

\section{Peter Hallman}

\section{(2) OpenEdition \\ 1 Journals}

\section{Electronic version}

URL: https://journals.openedition.org/scolia/1644

DOI: $10.4000 /$ scolia. 1644

ISSN: 2677-4224

\section{Publisher}

Presses universitaires de Strasbourg

\section{Printed version}

Date of publication: 9 July 2021

Number of pages: $69-92$

ISBN: 979-10-344-0091-1

ISSN: 1253-9708

\section{Electronic reference}

Peter Hallman, "Conditions sur la définitude dans les superlatifs arabes", Scolia [Online], 35 | 2021, Online since 09 July 2021, connection on 14 July 2021. URL: http://journals.openedition.org/scolia/ 1644 ; DOI: https://doi.org/10.4000/scolia.1644

\section{(c) (i) (ㅇ)}

Les contenus de la revue Scolia sont mis à disposition selon les termes de la Licence Creative Commons Attribution - Pas d'Utilisation Commerciale - Partage dans les Mêmes Conditions 4.0 International. 
SCOLIA 35/2021, p. 69-92.

\title{
Conditions sur la définitude dans les superlatifs arabes
}

\author{
Peter HALLMAN \\ Austrian Research Institute for Artificial Intelligence \\ peter.hallman@ofai.at
}

\section{Introduction}

Szabolcsi (1986) and Heim (1999) point out that a superlative construction like (1) has two readings, one where we compare mountains in terms of height (the 'absolute' reading) and another where we compare Sarah to other mountain climbers in terms of the how high a mountain they climbed (the 'relative' reading).

1) Sarah climbed the highest mountain.

They analyze the semantic contrast between the two readings as a difference in the scope of the superlative morpheme -est (see also Hackl, 2009). On the absolute reading, -est moves to the edge of the $\mathrm{NP}$ containing it, as sketched in (2a). On the relative reading, it moves further to the edge of the VP containing it, sketched in (2b).

2) a. Sarah climbed the [NP est [NP high mountain]]

b. Sarah [VP est [VP climbed a high mountain]]

The superlative morpheme -est itself denotes a function that maps a degree relation to an individual predicate. The individual predicate is true of the individual that bears the degree relation to a higher degree than any other individual in a contextually salient contrast set $C$, or as (3) puts it, if the individual bears the degree relation to a degree that no other individual bears the degree relation to.

3) $[[-\mathrm{est}]] C_{=} \lambda R_{<\mathrm{d},<\mathrm{e}, \mathrm{t}>>} \lambda x_{\mathrm{e}} \cdot \exists d[R(x, d) \& \forall y \in C[y \neq x \rightarrow \neg R(y, d)]]$

In the absolute reading in (2a), the degree relation is the NP high mountain; it holds of the pair $x$ (an individual) and $d$ (a degree) if $x$ 
is a mountain and $x$ is $d$-high. In (2b), the degree relation is the VP climb a high mountain, which holds of the pair $x$ and $d$ if $x$ climbed a $d$-high mountain. The largest bracketed constituent in (2a) describes a mountain higher than any other mountain. The largest bracketed constituent in ( $2 b$ ) describes a person who climbed a mountain higher than any mountain any other person climbed. A side effect of this latter interpretation is that the mountain that Sarah climbed is not necessarily the highest of all the mountains in the world, or even in the mountain climbing situation under consideration. On this reading, we can still say (1) if there are mountains higher than the one Sarah climbed, as long as no relevant person climbed them.

A puzzling aspect of this analysis of the two readings of the superlative is the following: in the surface structure, the superlative DP is morphologically definite, but the semantic definiteness of the superlative DP depends on the scope of -est. It is semantically definite when -est stays in the DP containing it in the surface structure (the absolute reading) but semantically indefinite if -est moves outside that DP in the semantic composition, or "Logical Form" ("LF"). In that case, the highest mountain must be interpreted existentially on par with the indefinite a high mountain at LF, as illustrated in (2b). Otherwise, the degree relation would assert of the pair $x$ and $d$ that $x$ climbed the unique mountain with height $d$ and that all individuals $y$ in the contrast set did not climb the unique mountain with height $d$. But this would be asserting that Sarah climbed the unique highest mountain, precisely what the relative reading of (1) does not entail. So it is crucial that the definiteness that the definite article the contributes is somehow cancelled out at LF when -est moves out of that DP.

This approach to the meaning of the superlative raises the question of why superlative DPs are morphologically definite on both readings, and what it means for definiteness to be 'canceled out'. Problems surrounding these issues have engendered counterproposals to the movement approach to relative readings that seek to attribute meaning to the definite article, explaining its presence in both contexts. The following section reviews several of these, while section 2 turns to Arabic data that points to a functional role for morphological definiteness in superlative constructions. 


\section{Previous approaches}

Szabolcsi (1986) points out that the 'definiteness cancellation' aspect of the movement analysis seems to be empirically reflected in the possibility of putting superlative DPs in existential contexts like object of have or subject of the existential-there construction, as (4) illustrates. These contexts normally do not admit definite DPs, as (5) illustrates. The examples in (4) are only acceptable on the relative reading of the superlative; in (4a) we compare John to others in terms of how smart their sisters are, in (4b) we compare yesterday with other days in terms of how large a box of chocolate was on the table on that day. This supports the conclusion that relative superlatives are semantically indefinite.

4) a. John has the smartest sister

b. There was the largest box of chocolate on the table yesterday.

5) a. ${ }^{*}$ John has the sister.

b. ${ }^{*}$ There was the box of chocolate on the table yesterday.

Why then are relative superlatives morphologically definite? Traditional analyses of the definite article attribute to it both a uniqueness and an existence condition (Frege, 1893; Russell, 1905). In a context in which there is more than one mountain or no mountain at all, the definite the mountain fails to refer. In contrast, Coppock and Beaver $(2012,2014,2015)$ claim that definiteness per se contributes only a weak uniqueness presupposition to the effect that there is not more than one entity with the relevant property. An existence presupposition is contributed by a null type shift they call 'determinacy' that is contingent on the context in which the definite occurs. Superlative DPs, they claim, are 'merely' definite and not determinate. Consequently, sentences like (6) are acceptable, since the DP the largest prime number does not presuppose the existence of a largest prime number, but merely that there is not more than one largest prime number; there may be none.

6) Seven is not the largest prime number.

As Coppock and Beaver (2014) point out, this approach does not actually help the movement analysis. Assuming that -est moves to the VP edge in (1) on the relative reading but that the remnant DP the $d$-high mountain carries the presupposition that there is no more than one mountain of height $d$, then (1) entails that there is no mountain 
higher than the mountain that Sarah climbed, precisely the entailment we wanted to avoid by moving -est. Accordingly, Coppock and Beaver claim that relative readings do not involve displacement of -est, and claim that in fact the relative reading is a subcase of the absolute reading where we contextually restrict the domain of the superlative noun to those members of its denotation that are relevant in the discourse situation-in (1) the mountains that someone climbed. Heim (1999) considers this possibility, too, but rejects it on the basis of examples like (7). We can utter (7) in a context where we have asked several people 'How high a mountain do you want to climb?' and these individuals have responded with a specific height, without having any particular mountain in mind. Sharvit and Stateva (2002) refer to this as an 'upstairs de dicto' reading, 'upstairs' because it involves wide scope of -est, but 'de dicto' because no particular mountains are referred to. In the context sketched above, there is no set of mountains that we could restrict the denotation of mountain to in order to say that John wants to climb the highest of these, since the mountain climbers do not have desires about specific mountains, only heights, making this example problematic for an in situ theory of superlative interpretation. But this reading is generated straightforwardly by moving est over the modal verb want as illustrated in (7b). (7a) holds if John exceeds others in terms of the height he wants the mountain he climbs to have, without having a particular mountain in mind. This is just the upstairs de dicto reading of (7a).

7) a. John wants to climb the highest mountain.

b. John [VP est [VP wants to climb a high mountain ]]

Coppock and Beaver (2014) respond that upstairs de dicto readings are arguably not limited to superlative constructions. If John wants to eat a bacon sandwich, (8) is true, even if non-kosher is not part of John's desire (I have modified Coppock and Beaver's example (42), (2014: 191), slightly to make it parallel to (7)). Coppock and Beaver conclude that the appropriate treatment of upstairs de dicto readings is orthogonal to the proper treatment of superlative constructions.

8) John wants to eat a non-kosher sandwich.

In (8), we have replaced bacon with a property it entails (non-kosher). In a parallel treatment of $(7 \mathrm{a})$, where we know, for example, that John wants to climb a $7,000 \mathrm{~m}$ mountain, Mary a $6,000 \mathrm{~m}$ mountain, and 
Jane a $5,000 \mathrm{~m}$ mountain, we have replaced $7,000 \mathrm{~m}$ with the property highest. But, unlike the entailment from bacon to non-kosher, 7,000m only entails highest in a context in which no mountain is higher than $7,000 \mathrm{~m}$. So we have to circumscribe the mountains to license this replacement, but taking the mountains into account is precisely what we cannot do in upstairs de dicto contexts, where there are no particular mountains, only height-desiderata. While the parallel between ( $7 a)$ and (8) is intriguing and warrants further investigation, it does not seem to be a foregone conclusion that (7a) can be analyzed along the lines of whatever the appropriate analysis of (8) is.

Another analysis of the superlative relevant to the analysis I present in section 3 is the approach taken by Bumford (2017). He claims that definites carry an existence and a uniqueness condition, but that these conditions are not necessarily enforced at the point at which the definite article enters the derivation. It is possible to delay the point at which the semantic context of the article is integrated into the semantic composition. This allows Bumford to capture a parallel between so-called 'Haddock' examples like (9a) (after Haddock 1987) and superlative constructions like (9b).

9) a. the rabbit in the hat

b. the rabbit in the biggest hat

Example (9a) successfully describes a rabbit even in a situation in which there are multiple rabbits and multiple hats, as long as there is only one rabbit in a hat. Example (9b) even admits the possibility that several rabbits are in hats, but refers to the rabbit in the hat that is larger than any other hat that a rabbit is in. Bumford claims that the test of the presuppositions of the embedded definite article in the hat in (9a) is delayed to where the higher article in the rabbit is, so that uniqueness is tested not for rabbits but for pairs $x$ and $y$ such that $x$ is a rabbit, $y$ a hat, and $x$ is in $y$. Similarly, he claims, in (9b) we test the definiteness of the superlative description together with the superlative description itself at the level of the higher definite article, so we test for pairs $x$ and $y$ whether $x$ is a rabbit, $y$ a hat, $x$ is in $y$, and $y$ is larger than any other hat that a rabbit is in.

Bumford's analysis does not delete definiteness from relative superlatives but gets definiteness 'out of the way' by delaying not just the point at which the superlative is integrated into the semantic 
composition but in tandem, the point at which definiteness is integrated. But it is not obvious how Bumford's analysis will accommodate upstairs de dicto readings discussed above. Definiteness at any level in (7a) conflicts with the modality introduced by want. Even if we delay the definiteness and superlative tests in (7a) to a point above the modal verb, we assert that there is one unique pair $x$ and $y$ such that $x$ is John, $x$ wants to climb $y$ and $y$ is a higher mountain than anyone else wants to climb. This requires a referent for $y$ in the evaluation world, but (7) makes no such commitment. Further, it does not seem like delaying the definiteness test in (6) will help capture what that example means.

There are, furthermore, apparently constraints on delaying definiteness that are obviated by the presence of the superlative. According to Bumford, (4a) is grammatical because the definiteness test can be delayed to a point external to the existential context, meaning the presupposition of the smartest sister is not active within the existential context. Yet, delaying definiteness is apparently not possible in the ungrammatical (5a), where the superlative is missing. This means that what licenses the indefinite interpretation of the smartest sister is the superlative, and in particular the fact that the superlative is interpreted external to the existential context. Bumford's analysis does not fully resolve the question of how these things are connected.

For reasons of space I pass over other analyses that also eschew -est movement but attribute a different meaning to the in absolute and relative superlatives (Sharvit and Stateva, 2002; Krasikova, 2012). These analyses have in common with those reviewed above that all at least implicitly assume that absolute superlatives are referential in argument positions, i.e. truly semantically definite (or 'determinate' in Coppock and Beaver's (2015) terms). However, some evidence speaks against even this. Suppose the two highest mountains in Kenya have exactly the same height, and Mary climbed one of them. As Hallman (2016) points out, we can truthfully utter (10) in this scenario.

10) Mary didn't climb the highest mountain in Kenya.

There's another mountain there that's exactly as high.

The first sentence in (10) denies not that Mary climbed any particular mountain but that the mountain she climbed is the highest in Kenya. This in turn means that the object DP in (10) does not refer to a particular mountain, but rather to the description a mountain higher 
than any other mountain in Kenya. This example is similar to Coppock and Beaver's example in (6) except that the superlative DP occurs in an argument position in (10), rather than in predicate position. The idea that even absolute superlatives may be semantically indefinite is supported by the fact that they are not subject to the Familiarity Condition that definites normally obey-that the referent of a definite DP be mentioned previously in the discourse. Out of the blue, the mountain in (11) is infelicitous but the highest mountain in Kenya is felicitous. The fact that absolute superlative DPs can be used to introduce new discourse referents reinforces the conclusion that they are semantically indefinite.

11) Last year Mary climbed \#the mountain / the highest mountain in Kenya.

I take this brief review of some of the relevant literature to indicate that the role of definiteness in superlatives and the connection between definiteness and the scope of the superlative is not entirely resolved. While many questions remain open, in what follows I accept Heim's conclusion that -est movement is necessary to derive upstairs de dicto readings, and accordingly that -est movement is responsible for the relative/absolute distinction. In consequence, I assume that relative superlatives are purely indefinite, since even weak definiteness in Coppock and Beaver's sense is incompatible with the movement theory. Moreover, examples like (10) and (11) suggest that even absolute superlatives are-or at least can be-semantically indefinite. But these conclusions make the question of why superlatives are always morphologically definite in English all the more urgent. In the remainder of this paper, I attempt to answer this question on the basis of data from contemporary Syrian Arabic, where the superlative morpheme displays a degree of syntactic mobility in the surface structure and the surface position of the superlative morpheme modulates the occurrence of morphological definiteness.

\section{Superlatives in Syrian Arabic}

In Syrian Arabic, adjectives typically follow the noun they modify, as illustrated in (12a). There is no indefinite article in Syrian Arabic; a bare noun is interpreted as indefinite. Definiteness is marked by the 
definite article $l$-, which occurs on the head noun and is copied onto all adjectival modifiers of the noun (12b). The definite article assimilates to a following coronal consonant (other than $/ 3 /$, for historical reasons).

12) a. sa:ra tals-it Sala zabal Sa:li

Sarah climbed-3Fs on mountain high

Sarah climbed a high mountain.

b. sa:ra talৎ-it Sala l-zabal l-Sa:li

Sarah climbed-3Fs on the-mountain the-high

Sarah climbed the high mountain.

Superlative adjectives are morphologically related to their superlative forms by virtue of shared root consonants. Regardless of the prosodic form of the adjective, the superlative has the templatic shape $a C_{1} C_{2} a C_{3}$, where $C_{1}-C_{3}$ represent the root consonants shared with the adjectival base. In this manner, abSad 'furthest' represents the superlative form of baSi:d 'far', ashal 'easiest' the superlative of sahl 'easy', asla (/ aSlay/) 'highest' the superlative of Sa:li (/Sa:liy/) 'high', etc. Superlative adjectives may modify a noun in the usual way for adjectives, following the noun. In this case, the noun must be morphologically definite, as in English. In accordance with the generalization that (12b) illustrates, both the noun and the superlative adjective bear the definite article, as illustrated in (13).

13) sa:ra tals-it Sala l-zabal l-aSla.

Sarah climbed-3Fs on the-mountain the-highest

Sarah climbed the highest mountain.

This structure has both a relative and an absolute reading. It can be uttered in a context where Sarah climbed Mt. Everest (the absolute highest mountain in the world) and there were no other climbers, or a context in which there were a variety of climbers and Mary has climbed a higher mountain than any of the other climbers, but not necessarily the highest mountain in the world. The latter reading is salient in a question like (14) when the speaker does not know who has climbed which mountains.

14) mi:n bayna:t-kun talaS Sala l-zabal l-aSla? who among-you climbed on the-mountain the-highest Which of you climbed the highest mountain?

As in other languages, all modifiers of the noun fall under the scope of the superlative even on the absolute reading, including relative 
clauses (Heim, 1999; Stateva, 2000; Matushansky, 2008; Cinque 2010). By way of illustration, at $7,570 \mathrm{~m}$, Gangkhar Puensum is the highest mountain in the state of Bhutan. Several attempts to climb Gangkhar Puensum before 1994 failed, and in 1994 the climbing of mountains over $6,000 \mathrm{~m}$ was prohibited in Bhutan. As a result, Gangkhar Puensum is the highest mountain that has never been climbed. This proposition is expressed as (15) in Arabic.

15) Gangkhar Puensum l-zabal l-aSla illi ma talaS Sale:- $h$ hada.

Gangkhar Puensum the-mountain the-highest that not climbed on-it anyone

Ganghar Puensum is the highest mountain no one has ever climbed.

The relative clause is in the semantic scope of the superlative. We are not asserting that Gangkhar Puensum is both the highest mountain (that would be Mount Everest), and also one that no one has ever climbed (which is not true of Mount Everest). Rather, the sentence in (15) appears to have the logical form in (16). The operator EST derives a description of the element in the denotation of the bracketed constituent that satisfies that description to the highest value of $d$. I represent the Arabic LF using English morphemes for perspicuity and in the remainder of the paper I use small cap 'EST' to refer to the superlative morpheme non-language specifically. 'EST' is expressed as -est in English and as the template $a C C a C$ in Arabic.

16) $\lambda x$. EST $[$ [mountain $(x) \& h i g h(x, d) \& \neg \exists y \operatorname{climbed}(y, x)$ ]

This means that even though the superlative adjective occurs between the noun and the relative clause in Arabic, the superlative morpheme is interpreted external to the constituent containing all three (the noun, the relative clause, and the adjective that bears the superlative morpheme in the surface structure). This accords with the analyses of Szabolcsi (1986) and Heim (1999), which derive absolute readings by movement of the superlative morpheme to the edge of the nominal constituent containing the superlative adjective.

It is an interesting property of Arabic that the superlative adjective may appear in the surface structure in a position corresponding to the position of EST in (16), as illustrated in (17) (see Hallman 2016). In this case, all morphological indications of definiteness disappear. 
17) Gangkhar Puensum aSla zabal (illi) ma talaS Sale:- $h$ hada.

Gangkhar Puensum highest mountain (that) not climbed on-it anyone Ganghar Puensum is the highest mountain no one has ever climbed.

In (17), the order of superlative adjective and noun is reversed, and neither may bear the definite article. Further, the relative pronoun illi becomes optional in this case. In Syrian Arabic, the relative pronoun illi is systematically optional when the head noun the relative clause modifies is indefinite, as illustrated in (18).

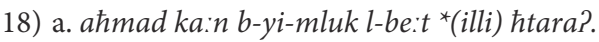

Ahmad was IND-3Ms-own the-house ${ }^{*}$ (that) burned.down

Ahmad owned the house that burned down.

b. ahmad ka:n b-yi-mluk be:t (illi) htara?.

Ahmad was IND-3Ms-own house (that) burned.down

Ahmad owned a house that burned down.

I refer to the structure in (15) as the 'morphologically definite' superlative and the structure in (17) as the 'morphologically indefinite' superlative. There is no difference in meaning between the two formats for the superlative, as I demonstrate in detail below.

Before doing so, I mention one additional format for the superlative which is a variation on the indefinite format. It is possible for the superlative morpheme to occur in the prenominal position seen in (17) while the adjectival associate stays in situ in post-nominal position. The superlative morpheme takes the form aktar in this case, the superlative form of the quantity adjective kti:r 'much/many'. I assume the base adjective is vacuous in this case and is used here as a pleonastic morphological base for the superlative template. The adjectival associate appears in situ in this case, in the same position it occurs in in the definite superlative structure illustrated in (15). This situation is illustrated in (19).

19) Gangkhar Puensum aktar zabal Sa:li (illi) ma țalaS Sale:- $h$ hada. Gangkhar Puensum most mountain high (that) not climbed on-it anyone

Ganghar Puensum is the highest mountain no one has ever climbed.

This structure, too, expresses the same proposition as those in (15) and (17), suggesting that all these share the logical form in (16). Indeed, the surface form of the indefinite superlative bears a striking resemblance to the logical form illustrated there, in which the superlative morpheme (together with the associated adjective in (17), without it in (19)) occurs 
at the left edge of the DP containing its scalar associate, where it scopes over all the descriptive content in that DP. This raises the question of why the occurrence of the definite article correlates with the position of the superlative morpheme. I will claim that the definite article is an overt scope marker for the superlative. But first I establish below that morphological definiteness does not make any semantic contribution to the meaning of superlative constructions in Arabic that is not already part of the meaning of morphologically indefinite superlatives.

The first similarity between the definite and indefinite superlative is that both are compatible with both relative and absolute readings, as mentioned above (see also Al-Bitar, 2019 : 56-57). All the examples in (20) assert that Sarah climbed the mountain called Jabal Al-Shaykh, which at $2,814 \mathrm{~m}$ is the highest mountain in Syria; the modifier b-su:ri:ya strongly emphasizes the absolute reading (see Farkas and Kiss, 2000).

20) a. sa:ra tals-it Sala al-zabal al-aSla b-su:ri:ya.

Sarah climbed-3Fs on the-mountain the-highest in-Syria Sarah climbed the highest mountain in Syria.

b. sa:ra tals-it Sala aSla zabal b-su:ri:ya.

Sarah climbed-3Fs on highest mountain in-Syria

Sarah climbed the highest mountain in Syria.

c. sa:ra tals-it Sala aktar zabal Sa:li b-su:ri:ya.

Sarah climbed-3Fs on most mountain high in-Syria

Sarah climbed the highest mountain in Syria.

All three formats can also have a relative reading, as if someone asks the questions in (21) without knowing which mountains anyone climbed, and perhaps even knowing that no one climbed the absolute highest mountain accessible in the discourse context.

21) a. mi:n talas Sala al-zabal al-aSla? who climbed on the-mountain the-highest Who climbed the highest mountain?

b. mi:n tala Sala aSla zabal? who climbed on highest mountain Who climbed the highest mountain?

c. mi:n talaS Sala aktar zabal Sa:li? who climbed on most mountain high Who climbed the highest mountain?

Recall that Szabolcsi (1986) and Heim (1999) claim that in English, absolute superlatives are definite and relative superlatives indefinite. If 
this is so, it is easy to imagine that a language with both morphologically definite and indefinite superlatives would apply the morphological distinction along these lines, using the definite superlative to express absolute readings and the indefinite superlative to express relative readings. But this does not appear to be the case in Arabic. Both morphologically definite and indefinite superlatives are compatible with both absolute and relative readings and, as illustrated in (15), (17) and (19), display the same scope with respect to a relative clause (the relative clause restricts the description the superlative applies to in both cases).

The morphologically definite and indefinite superlative structures in Arabic also do not display a contrast that has been shown to distinguish morphologically definite and indefinite superlatives in some Slavic languages. Pancheva and Tomaszewicz (2012) report that some Slavic languages display a 'DP-internal relative reading', where a constituent internal to the superlative DP designates the subject of comparison. For example, the Bulgarian example (22) below has a reading in which (the Irish band) U2 designates the subject of comparison, so we are comparing $\mathrm{U} 2$ to other bands in terms of how good the albums by that band are that Ivan has. No such reading is available to the English counterpart Ivan has the best albums by U2, whose only relative reading compares Ivan to others in terms of how good the albums by U2 they have are. Similarly, (23) has a reading that says that the students that Ivan met from London were younger than the students he met from any other city. Here we compare the DP-internal constituent London to other cities in terms of how young the students from that city were that Ivan met. Again, the only relative reading the English counterpart Ivan met the youngest students from London has is one in which we compare Ivan with others in terms of how young the students from London they met were. In the English counterparts to these examples, the DP-internal constituents U2 in (22) and London cannot function as the subject of comparison for the superlative.

22) Ivan ima naj-dobri albumi na/ot U2.

Ivan has EST-good albums of/by U2

(i) Ivan has better albums by U2 than anyone else does.

(ii) Ivan has better albums by U2 than by any other band. 
23) Ivan se zaponzna s naj-mladi studenti ot London.

Ivan REFL met with EST-young students from London

(i) Ivan met younger students from London than anyone else did.

(ii) Ivan met younger students from London than from any other city.

Pancheva and Tomaszewicz (2012) link DP-internal relative readings to the fact that the languages in question do not have a definite article, which makes the DP transparent in a way that licenses these readings. In support of this claim, they point out that unlike most other Slavic languages, Bulgarian (and the closely related Macedonian) have an optional definite article, and the presence of this article in superlatives blocks the DP-internal relative reading, as illustrated in (24)-(25).

24) Ivan ima naj-dobri-te albumi na/ot U2.

Ivan has EST-good-the albums of/by U2

Available: Ivan has better albums by U2 than anyone else does.

Not available: Ivan has better albums by U2 than by any other band.

25) Ivan se zaponzna s naj-mladi-te studenti ot London.

Ivan REFL met with EST-young-the students from London

Available: Ivan met younger students from London than anyone else did.

Not Available: Ivan met younger students from London than from any other city.

When the superlative DP is morphologically definite, indicated by the suffix -te on the adjective in (24) and (25), material internal to that $\mathrm{DP}$ is no longer accessible as subject of comparison. If this distinction really correlates with definiteness cross-linguistically, we might expect Arabic to exhibit the same asymmetry between superlative DPs that lack the definite article like in (20b) and those that bear the definite article like in (20a).

No such contrast is found in Arabic. Syrian Arabic speakers generally do not accept DP-internal relative readings even in morphologically indefinite superlatives. The counterpart of (22)/(24) is shown in (26). Its morphologically definite counterpart is shown in (27). Both display an absolute reading (not notated) and a subject-oriented relative reading where we compare Sarah to other individuals in terms of how good the albums by U2 they own are. The two formats are synonymous; adding the definite article in (27) does not exclude any readings available in (26). The same holds for counterparts to (23)/(25) (not shown).

26) sa:ra Sand-a ahsan albu:ma:t la-U2.

Sarah at-her best albums by-U2 
Available: Sarah has better albums by U2 than anyone else does. Not available: Sarah has better albums by U2 than by any other band.

27) sa:ra Sand-a al-albu:ma:t al-ahsan la-U2.

Sarah at-her the-albums the-best by-U2

Available: Sarah has better albums by U2 than anyone else does.

Not available: Sarah has better albums by U2 than by any other band.

Tomaszewicz-Özakın (2020) points out that languages like Bulgarian also allow the head noun in the superlative DP to function as the subject of comparison when focus marked. In such languages, the counterpart of an expression like that in (28a) may be interpreted to assert that the highest thing that Maria hung on the wall was the clock. This reading is generally unavailable in Arabic in both the indefinite format in (28a) and the definite format in (28b), where bold indicates focal stress. Neither (28a) nor (28b) may generally describe a situation in which Maria hung a tapestry, a picture, a mirror and a clock on the wall, and she hung the clock in a position higher than all the other things she hung on the wall. These judgments reflect the majority view; I add the caveat 'generally' here because Syrian speakers do in fact occasionally accept DP-internal relative readings, probably subject to variation in how speakers parse syntactic relations internal to the DP. However, when speakers accept a DP-internal reading for an indefinite superlative, they systematically accept it for the definite counterpart as well. Again, adding definiteness does not exclude any readings available to the indefinite counterpart.

28) a. \# ma:ri:a Sall?-it aSla sa:Sa Sa-l-ћayyit.

Maria hung-3Fs highest clock on-the-wall

\#Maria hung the highest clock on the wall.

b. \# ma:ri:a Yall?-it s-sa:Sa al-aYla Ya-l-hayyit.

Maria hung-3Fs the-clock the-highest on-the-wall

\#Maria hung the highest clock on the wall.

Further, if definiteness contributes an existence presupposition in the Arabic morphologically definite superlative format, we would expect this format to be incompatible with the predicative reading of superlatives that we find in English examples like Coppock and Beaver's (2015) example (6) mentioned above, whose Arabic counterpart is shown in (29) in the definite (29a) and indefinite (29b) format. If the Arabic definite superlative were referential, it would be expected to 
refer to the unique highest prime number in (29). But like English, neither example in (29) presupposes the existence of a highest prime number.

29) a. sabৎa ma:-nu al-ৎadad al-awwali al-akbar. seven not-3Ms the-number the-prime the-largest Seven is not the largest prime number.

b. sabSa ma:-nu akbar Sadad awwali. seven not-3Ms number prime largest Seven is not the largest prime number.

The situation in Arabic is puzzling. Recall that Szabolcsi (1986) and Heim (1999) claim that superlatives in English, which are always morphologically definite, are semantically definite on their absolute reading and semantically indefinite on their relative reading. Arabic has morphologically definite and indefinite superlatives but this contrast bears no relation to the semantic definite $v s$ indefinite contrast that Szabolcsi and Heim propose.

In the respects described above, Arabic superlatives in both the definite and indefinite format are interpreted exactly like English superlatives. English superlatives are always morphologically definite, though they are not always semantically definite and some evidence reviewed in section 1 suggests that they are always semantically indefinite. Arabic superlatives are morphologically definite when the superlative morpheme occurs in the usual post-nominal position for adjectives, and morphologically indefinite when it occurs prenominally. The question of what circumstances trigger morphological definiteness in Arabic may help us understand why superlative DPs are ever morphologically definite at all, if their morphological definiteness at least sometimes does not reflect semantic definiteness. I pursue this question in the following section.

\section{Structural conditions on definiteness in superlatives}

Even though the superlative morpheme can be separated from the associated adjective in (20c), the bare superlative morpheme (in the form of aktar) cannot appear by itself in the post-nominal canonical position of adjectives, as illustrated in (30). Making any of the constituents in (30) indefinite does not improve the judgment, nor does re-ordering the adjectives. 
30) ${ }^{\star}$ sa:ra talG-it Sala l-zabal l-aktar l-Sa:li.

Sarah climbed-3Fs on the-mountain the-most the-high

(Sarah climbed the highest mountain.)

The ungrammaticality of (30) is part of a larger generalization. Prenominal aktar 'most' may be separated from its scalar associate more dramatically than we see in examples like (20c). In those examples, the pre-nominal superlative morpheme associates with a scalar adjective that follows the noun. But the scalar associate of prenominal aktar may be contained within a modifier of the noun, as shown in (31).

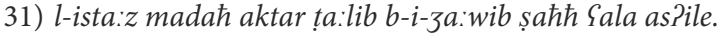
the-teacher praised most student IND-3Ms-answer right on questions The teacher praised the student who answered the most questions correctly.

In (20c), the scalar associate of aktar is a gradable adjective modifying the noun that aktar precedes, in (31) it is a plural noun (as?ile 'questions') inside a relative clause modifying the noun that aktar precedes. Prenominal aktar can take any gradable term as a scalar associate as long as it is syntactically accessible (see Hallman 2016 on conditions for accessibility). In (32) it is a gradable verb in a relative clause, in (33) an adverbial prepositional phrase in a relative clause.

32) sa:ra aktar ta:libe b-ti-sta:hil l-za:yze.

Sarah most student IND-2Fs-deserve the-prize

Sarah is the student who deserves the prize the most.

33) sa:ra ka:n-it aktar mitna:fs-e bi-t-su:? b-sirGa.

Sarah was-3Fs most competitor-Fs IND-2Fs-drive with-speed

Sarah was the competitor who drove the fastest.

In none of these examples can aktar occur as a post-nominal adjective modifying the head noun that the relative clause also modifies, as the examples in (34) show.

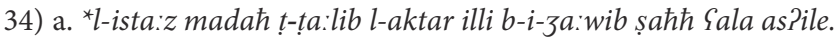
the-teacher praised the-student the-most that IND-3Ms-answer right on questions

(The teacher praised the student who answered the most questions correctly. $)^{1}$

1 Here and below, parentheses enclose translations to ungrammatical sentences. They say not what the sentence means, but what it would mean if it were grammatical. 
b. ${ }^{*}$ sa:ra t-ța:libe l-aktar illi b-ti-sta:hil l-za:yze.

Sarah the-student the-most that IND-2FS-deserve the-prize

(Sarah is the student who deserves the prize the most.)

c. ${ }^{*}$ sa:ra ka:n-it l-mitna:fs-e l-aktar illi bi-t-su:? b-sirSa.

Sarah was-3Fs competitor-Fs the-most that IND-2FS-drive with-speed (Sarah was the competitor who drove the fastest.)

The examples in (34) are parallel to (30), where l-aktar 'the-most' appears as a post-nominal adjective next to its scalar associate, the adjective $l-? a: l i$ 'the-high'. In the examples in (34), l-aktar also occurs as a modifier of a noun and its scalar associate is embedded in a relative clause modifying that noun. Again, it is not in principle impossible for the superlative morpheme in the form of aktar to be separated from its scalar associate, but only when aktar is pre-nominal.

The examples in (31)-(33) have counterparts in (35a)-(35c) in which, in parallel to the English translations there, the superlative morpheme occurs locally to its scalar associate, internal to the relative clause. In Arabic, the adverbial superlative is put to use to form superlatives of plural nouns (35a), in addition to gradable verbs (35b) and adverbs (35c). The adverbial superlative counterpart to English the most is formed in Arabic by combining the superlative template, again in the default form aktar, with a dummy noun - wa: $\hbar i d$ 'one' or feminine watd-e 'one-Fs' when the subject of comparison is human, or $f i$ 'thing' when it is non-human. Like other adverbs in Arabic, aktar wa: $\hbar i d(e) / \int i$ may occur in a variety of positions and need not be directly adjacent to its scalar associate.

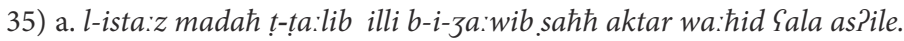
the-teacher praised the-student that IND-3Ms-answer right most one on questions

The teacher praised the student who answered the most questions correctly.

b. sa:ra t-ta:libe illi b-ti-sta:hil l-za:yze aktar wahd-e.

Sarah the-student that IND-3Fs-deserve the-prize most one-FS

Sarah is the student who deserves the prize the most.

c. sa:ra ka:n-it l-mitna:fs-e illi bi-t-su:? aktar wahd-e b-sirYa.

Sarah was-3Fs the-competitor-Fs that IND-3FS-drive most one-FS with-speed

Sarah was the competitor who drove the fastest.

In these surface structures, the superlative morpheme occurs local to its scalar associate within the relative clause, rather than prejacent 
to the NP that restricts the comparison set. But semantically, the superlative still has scope over the entire NP containing it in the surface structure. The object in (35a) names the student who answered more questions than any other student answered-ta:lib 'student' is part of the restriction on the set of entities being compared. These sentences, therefore, also have a logical form in which the superlative morpheme is external to the NP containing the nominal head and the relative clause modifying that nominal head.

It is of special interest for the present purposes that the DP containing the superlative adverb in the examples in (35) must be morphologically definite. Making the DP indefinite results in ungrammaticality, as (36) shows-the indefinite counterpart of (35a). The same holds for the other examples in (35). The English translation to (36) and other examples constructed on the same pattern is also ungrammatical.

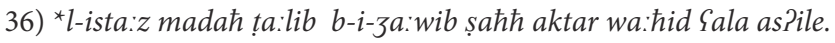
the-teacher praised student IND-3MS-answer right most one on questions

( ${ }^{\star}$ The teacher praised a student who answered the most questions correctly.)

Like English adverbial the most, the Arabic adverbial superlative aktar wa: hid 'most one' does not have an absolute reading (which would correspond to most of the questions). (36) is ungrammatical because the adverbial quantity superlative does not support an absolute reading and unlike the morphologically definite counterpart in (36) no relative reading is available either, so (36) is simply ungrammatical.

The data above exemplify the generalization that when a modifier of an NP contains a superlative morpheme, that NP must project a definite DP. This generalization holds for the ordinary post-nominal superlative shown in (3b), repeated in (37a) below, where modifying adjective Sa:li 'high' bears the superlative morpheme. If we remove definiteness from (37a), we get (37b), which is not ungrammatical, but which is no longer a superlative construction. A post-nominal elative adjective in an indefinite DP is interpreted as a comparative adjective. It may be followed by a PP headed by the preposition min 'from' naming the standard of comparison. 
37) a. sa:ra talS-it Sala l-zabal l-aSla.

Sarah climbed-3Fs on the-mountain the-highest

Sarah climbed the highest mountain.

b. sa:ra tals-it Sala zabal aSla (min zabalf-fe:x).

Sarah climbed-3Fs on mountain higher (from Mount the-Shaykh)

Sarah climbed a higher mountain (than Mount al-Shaykh).

The relation of the comparative to the superlative is a matter of great interest which, however, is outside the scope of the present study (but see Al-Bitar, 2019). The significant aspect of the pair in (37) for the present purposes is that the superlative interpretation of the post-nominal elative adjective is not available if the DP it occurs in is indefinite. This is, on one hand, just like the structures in (34), where the superlative is incompatible with indefiniteness, as (36) shows, and on the other hand, it is like English, where a superlative DP cannot be indefinite, regardless of whether the superlative morpheme appears as an adjectival suffix, as shown in (38a), or within a relative clause, as in the translation to (36), repeated in (38b).

38) a. ${ }^{\star}$ Sarah climbed a highest mountain.

b. ${ }^{\star}$ The teacher praised a student who answered the most questions correctly.

In the examples discussed above, a DP contains a superlative morpheme which, by hypothesis, moves to the edge of that DP at LF. The definite article itself typically occurs at the left edge of DP, just where the superlative morpheme occurs at LF (though in Arabic it is also copied onto modifiers of NP; I assume this is morphological agreement with D). One possible role for vacuous definiteness in superlative constructions, then, is as a way of marking in the surface order the scope that EST has at LF.

The Arabic data described above support this hypothesis. In Arabic, it is possible for the superlative morpheme to occur at the left edge of the DP that it has scope over at LF. In this case, its surface position and its semantic scope coincide, and then the DP it scopes over is morphologically indefinite. This fits into the hypothesis proposed here because there is no impetus for scope marking of EST when EST itself sits in its LF scope position in the surface structure. This generalization applies in principle to both Arabic and English, except that in English the superlative is never displaced from its base position adjacent to its scalar associate in the surface structure, and so indefinite superlatives 
do not normally arise; the superlative's scope is always marked by definiteness.

The remarks above deal with cases in which EST has scope at the level of DP. In relative readings, EST has scope at the level of VP, but definiteness marking in the superlative DP is the same as in the absolute reading: the DP is morphologically definite (in Arabic and English) except when (in Arabic) the superlative moves to its left edge in the surface structure. See the examples in (21) in this connection, where the interrogative subject mi:n 'who' makes the relative reading prominent. These examples are saliently interpreted to be asking for which person it is the case that that person climbed a higher mountain than anyone else climbed. The LF of this reading looks like (39), where a high mountain is semantically indefinite.

39) who $x_{x}$ est ${ }_{d}$ [ $\exists y x$ climbed $y$ and $y$ is a d-high mountain]

If the scope-marking hypothesis about the occurrence of morphological definiteness in superlatives is correct, then the definite article marks not just the DP to which EST adjoins at LF but-in the configuration generating relative readings-any DP falling in between its surface position and its LF scope position. Again, if the superlative morpheme itself occurs at a DP edge in the surface structure, this itself functions as surface scope marking and that DP is not marked as definite. These considerations suggest that a mechanism like that stated in the 'Superlative Scope Marking Rule' below is at work in both Arabic and English. It vacuously inserts l-/the in any D slot between the LF and surface positions of the superlative morpheme EST, as an overt sign that EST has wider scope at LF than its surface position.

Superlative Scope Marking Rule: Morphologically mark D in the configuration $\left[\mathrm{EST}^{\prime} \ldots\right.$ [DP $\ldots$ EST $\ldots$ ]], where $\mathrm{EST}^{\prime}$ represents the LF position of the superlative morpheme and EST its surface position.

I assume that when the superlative occurs at the left DP edge in Arabic, that in this case the superlative morpheme is not fully included within the DP projection (perhaps it is an adjunct dominated by only one segment of DP and therefore not by the category DP, as Kayne (1994) proposes for adjuncts in general). This formulation of the generalization predicts that if EST occurs at a DP edge in the surface structure, as it may in Arabic, that DP will not be marked definite because that DP 
does not fall between the surface and LF position of EST, which are the same position in this case.

Farkas and Kiss (2000) discuss examples similar to (38) in connection with their claim that, contra Szabolcsi (1986), superlatives are not generally licensed by A-bar chains. They claim that if the operator associated with abstraction over individuals that forms the relative clause in (40) could license the superlative, (40) should mean that I know a man who climbed a higher mountain than any other man climbed, just what the definite counterpart means.

40) I know a man who climbed the highest mountain.

Unlike (38b), (40) is not ungrammatical. It merely has only an absolute reading for the highest mountain, where it asserts that I know a man who climbed a mountain higher than all other mountains. On this reading, we are not comparing men but mountains. Example (38b) does not have such a reading because adverbial the most does not support an absolute reading. The Arabic counterpart of (40) in (41) is just like its English counterpart. The head of the relative clause may be indefinite, but then only an absolute reading over mountains is available to the superlative within the relative clause. As usual, the indefinite (41a) and definite (41b) formats for the superlative are interchangeable here.

41) a. b-a-Srif zalame talaS Sala aSla zabal. IND-1s-know man climbed on highest mountain I know a man who climbed the highest mountain.

b. b-a-Srif zalame talaS Sala l-zabal l-aSla.

IND-1s-know man climbed on the-mountain the-highest

I know a man who climbed the highest mountain.

In order for the NP headed by man/zalame to fall in the scope of the superlative, it needs to be marked definite, as illustrated in (42) for English and (43) for Arabic. These sentences have both the absolute reading where asla zabal/highest mountain refers to the absolute highest mountain in the world and the relative reading where we compare men in terms of how high a mountain they climbed.

42) I know the man who climbed the highest mountain.

43) a. b-a-Srif $z$-zalame illi talaS Sala aSla zabal. IND-1s-know the-man who climbed on highest mountain I know the man who climbed the highest mountain. 
b. b-a-Srif z-zalame illi talaS Sala l-zabal l-aSla.

IND-1s-know the-man who climbed on the-mountain the-highest I know the man who climbed the highest mountain.

Both the mountain-oriented (i.e., absolute) reading of the examples in (43) and the man-oriented reading (i.e., relative with respect to men) designate a single man, but, I claim, not for the same reason. On the mountain-oriented (absolute) interpretation of the superlative, reference to a single man is the contribution of the definite article, which is not obligatory on this reading (recall this reading is compatible with an indefinite object noun, as (40) and (41) show). On the manoriented reading, reference to a single man is an entailment of the meaning of the superlative, which has scope over man/zalame on the man-oriented relative reading of (42) and (43). At that structural level, the superlative constituent describes a man that climbed a mountain higher than any mountain any other man climbed. There can only be one such man. But the fact that only one man can meet that description is not, I claim, directly related to the fact that man/zalame is definite in (42) and (43). Definiteness on the man-oriented relative reading of (42) and (43) marks the LF scope of the superlative morpheme EST.

I conclude that the definiteness of superlative DPs is conditioned configurationally, according to the generalization in the Superlative Scope Marking Rule. When EST passes over a DP boundary on the way to its LF position, that D position is marked definite. This is a kind of partial surface marking of the scope of EST, which does not always move to a scope position in the surface structure even in Arabic, and not at all in English. The occurrence of $l$-/the makes EST movement visible. Superlative DPs, however, are always semantically indefinite. This analysis reconciles evidence for semantic indefiniteness in both absolute and relative superlatives with their morphological definiteness, and explains the indefiniteness of Arabic superlatives in which the superlative morpheme itself occurs in the scope position otherwise held by the definite article.

\section{Conclusion}

I have endeavored to show that previous analyses of the superlative attribute too much meaning to the definite article. I have provided instead an analysis that involves EST movement, inheriting all the 
advantages of the movement analysis of Szabolcsi (1986), Heim (1999) and Hackl (2009), and corroborated by the observation that superlatives in Syrian Arabic can be displaced to an extent, as movement analyses predict. I have also claimed that superlatives are indefinite even on their absolute reading. This of course raises the question of what function the morphological definiteness of superlative constructions in both Arabic and English and many other languages has. I have suggested on the basis of Arabic facts that the marks a potential scope position for EST, and its occurrence marks, in the surface structure, the fact that EST has wider scope than its surface position. I note here lastly that the cross linguistically robust involvement of the definite article in marking the scope of EST is probably related to Matushansky's (2008) claim that superlative adjectives are fundamentally attributive, not predicative. Accordingly, the superlative morpheme is always embedded in a DP in the surface structure, and, according to Szabolcsi (1986) and Heim (1999), always raises to at least the edge of that DP for scope, if not further. There is, therefore, a certain inherent affinity between EST and $\mathrm{D}$, which may help explain the use of the definite article as a scope marker for EST.

\section{References}

AL-BITAR A. (2019), The Superlative in English and Syrian Arabic. MA thesis, Universität Tübingen.

BUMFORD D. (2017), Split-scope definites: Relative superlatives and Haddock descriptions, Linguistics and Philosophy 40, 549-593.

CINQUE G. (2010), The syntax of adjectives: A comparative study, Cambridge, Mass., MIT Press.

COPPOCK E. \& BEAVER D. (2012), Weak uniqueness: The only difference between definites and indefinites, in Chereches A. (ed.), Proceedings of SALT XXII, Washington, D.C., Linguistic Society of America, 527-544.

COPPOCK E. \& BEAVER D. (2014), A superlative argument for a minimal theory of definiteness, in Snider T., D'Antonio S. \& Weigand, M. (eds.), Proceedings of SALT XIV, Washington, D.C., Linguistic Society of America, 177-196.

COPPOCK E. \& BEAVER D. (2015), Definiteness and determinacy, Linguistics and Philosophy 38, 377-435. 
FARKAS D. \& KISS K. (2000), On the comparative and absolute readings of superlatives, Natural Language and Linguistic Theory 18, 417-455.

FREGE G. (1893), Über Sinn und Bedeutung [On sense and reference], Zeitschrift für Philosophie und Philosophische Kritik 100, 25-50.

HACKL M. (2009), On the grammar and processing of proportional quantifiers: most vs. more than half, Natural Language Semantics 17, 63-98.

HADDOCK N. (1987), Incremental interpretation and combinatory categorial grammar, in Proceedings of the 10th international joint conference on artificial intelligence, vol. 2, IJCAI Organization, 661-663.

HALLMAN P. (2016), Superlatives in Syrian Arabic. Natural Language and Linguistic Theory 34, 1281-1328.

HEIM I. (1999), Notes on superlatives, Ms., University of Texas, Austin.

KAYNE R. (1994), The antisymmetry of syntax, Cambridge, Mass., MIT Press.

KRASIKOVA S. (2012), Definiteness in superlatives, in Aloni M., Kimmelman V., Roelofsen F., Sassoon G., Schulz K. \& Westera M. (eds), Logic, language and meaning, Dordrecht, Springer, 411-420.

MATUSHANSKY O. (2008), On the attributive nature of superlatives, Syntax 11, 26-90.

PANCHEVA R. \& TOMASZEWICZ B. (2012), Cross-linguistic differences in superlative movement out of nominal phrases, in Arnett N. \& Bennett R. (eds), Proceedings of the 30th West Coast Conference on Formal Linguistics, Somerville, Mass., Cascadilla Press, 292-302.

RUSSELL B. (1905), On denoting, Mind 14, 479-493.

SHARVIT Y. \& STATEVA P. (2002), Superlative expressions, context, and focus, Linguistics and Philosophy 25, 453-504.

STATEVA P. (2000), In defense of the movement theory of superlatives, in Daly R. \& Riehl A. (eds), Proceedings of the Eastern States Conference on Linguistics (ESCOL) 1999, Ithaca, NY, CLC Publications, 215-266.

SZABOLCSI A. (1986), Comparative superlatives, in Fukui N. (ed.) MIT working papers in linguistics, vol. 8, Cambridge, Mass., MIT Press, 245-265.

TOMASZEWICZ-ÖZAKIN B. (2020), The semantics of the superlative quantifier -est, in Hallman P. (ed.), Interactions of degree and quantification, Leiden, Brill, 79-120. 